\title{
DONEPEZIL HYDROCHLORIDE MITIGATES CONSEQUENCES OF ACUTE MYOCARDIAL INFARCTION IN MALE ALBINO RATS
}

\section{BY}

Ahmed A. Abdelsameea

FROM

Pharmacology department-Faculty of Medicine-Zagazig University

\begin{abstract}
Background

Cholinesterase inhibitors are used for symptomatic treatment of mild to moderate Alzheimer's disease. These drugs have vagomimetic and anti-inflammatory properties that could be of interest also with respect to cardiovascular diseases.
\end{abstract}

Aim

The aim of the present work is to assess effects of pretreatment with donepezil hydrochloride, one of cholinesterase inhibitors, on acute myocardial infarction induced by coronary artery ligation in rats.

\section{Methods}

Rats were randomly divided into control, sham-operated, untreated-myocardial infarction, and donepezil hydrochloride-pretreated myocardial infarction groups. Donepezil hydrochloride was administered orally, $1 \mathrm{mg} / \mathrm{kg} / \mathrm{day}$, for six days then acute myocardial infarction was induced in $6^{\text {th }}$ day by ligation of the left anterior descending coronary artery. ECG and blood pressure were recorded. Triphenyltetrazolium chloride (TTC) stained ventricular slices were examined. The plasma levels of tumor necrosis factor- $\alpha(\mathrm{TNF}-\alpha)$ and cardiac troponin I (cTnI) were assessed. Catalase activity and glutathione levels in the myocardium were determined.

\section{Results}

Coronary artery ligation increased T-wave voltage with appearance of pathological Q-wave, tachycardia, decreased mean arterial pressure and pale areas (infarcts) in TTC-stained ventricular slices. The plasma levels of TNF- $\alpha$ and cTnI were increased while the myocardial catalase activity and glutathione levels were decreased. In donepezil hydrochloride-pretreated group T-wave voltage and heart rate were decreased and pathological Q-wave disappeared with decrements in infarct size and plasma levels of TNF- $\alpha$ as well as cTnI, while catalase activity and glutathione levels were increased in relation to untreated myocardial infarction group.

\section{Conclusion}

Pretreatment with donepezil hydrochloride decreased myocardial infarct size. This effect could be related to its negative chronotropic, anti-inflammatory, and antioxidant actions.

\section{Key words}


Myocardial infarction, donepezil hydrochloride, triphenyltetrazolium,
inflammation.

Corresponding Author: Ahmed A. Abdelsameea. Email:ahmedma_72@yahoo.com

\section{Introduction}

Acute myocardial infarction (AMI) is a global disease and a major cause of morbidity and mortality worldwide. Despite major advances in mechanical and pharmacological strategies to improve AMI injury, substantial mortality, morbidity, and socioeconomic burden still exists (Montecucco et al., 2016). The prevalence of the disease is continuously increasing particularly in advanced countries (Moran et al., 2014). The disease is usually results from complete occlusion of a coronary artery with a thrombus with subsequent necrosis of myocardial tissue (Amsterdam et al., 2014). Inflammatory cellular infiltration and myocardial remodelling occurs after AMI with destructive and exudative inflammation, which leads to increase in the necrotic area (Sarapultsev et al., 2012). In human patients with myocardial infarction, defective suppression, and impaired resolution of inflammation may be important mechanisms in the pathogenesis of remodeling and in progression to heart failure (Frangogiannis, 2012)

Association between Alzheimer Dementia (AD) and multiple cardiovascular risk factors such as hypertension, diabetes, atherosclerosis, dyslipidaemia and stroke has previously shown (Monacelli et al., 2014). Donepezil hydrochloride, a potent cholinesterase inhibitor, has been demonstrated to be effective in improving cognition in patients with $\mathrm{AD}$ (Winblad et al., 2001). In addition to its effect in $\mathrm{AD}$, the drug demonstrated beneficial anti-ischemic actions. Administration of donepezil hydrochloride significantly attenuated cerebral infarct volume in experimentally induced focal cerebral ischemia (Fujiki et al., 2005) as well as protected from cerebral ischemia/reperfusion induced brain injury. These effects resided in the ability of the drug to inhibit $\mathrm{Ca}^{2+}$ overload as well as its antioxidant action (Wang et al., 2014).

Normal functioning of the cardiovascular system depends on an adequate sympathetic-parasympathetic interaction. A decreased parasympathetic tone is detrimental for the myocardium and is associated with a worse prognosis of cardiovascular diseases, particularly heart failure secondary to a myocardial infarction (Gelpi, 2016). Although, a decreased parasympathetic activity is an independent risk factor after AMI, a few studies have investigated an alternative treatment targeting parasympathetic dysfunction (Castro et al., 2004). In addition, the use of anticholinesterases demonstrated beneficial effects on the cardiovascular system of AD patients (Monacelli et al., 2014).

The aim of the present work is to assess effects of pretreatment with donepezil hydrochloride, one of cholinesterase inhibitors, on the consequences of AMI induced by coronary artery ligation in rats. 


\section{Material and methods}

\section{Drugs}

Donepezil hydrochloride powder: Delta Pharma, Cairo, Egypt; Ethyl Carbamate (Urethane) crystals: Prolabo, Paris, France.

\section{Animals}

Adult male albino rats weighing 200-220 gm were purchased from the Faculty of Veterinary Medicine, Zagazig University, Egypt. The rats received a standard diet and water ad labitum. They were kept under standard humidity, natural light-dark cycle and temperature of $22 \pm 1^{\circ} \mathrm{C}$ in plastic cages, and each cage containing 6 rats in animal house of Faculty of Medicine Zagazig University. All experimental protocols were approved by the Ethics Committee of Zagazig University.

\section{Experimental design}

48 male albino rats were randomly divided into 4 equal groups; control, sham operated, untreated myocardial infarction, and donepezil hydrochloride-pretreated myocardial infarction groups. In the latter group, donepezil hydrochloride was administered orally, $1 \mathrm{mg} / \mathrm{kg} /$ day, dissolved in distilled water for six days then coronary ligation was induced 2 hours after the last dose. The dose of donepezil hydrochloride was equivalent to human dose, $10 \mathrm{mg} /$ day, (Winblad et al., 2006) and converted to rat dose according to Reagan-Shaw et al. (2008). Other groups received distilled water, $2 \mathrm{ml} /$ rat, p.o., daily.

\section{Induction of AMI}

Rats were anesthetized with urethane, $1.75 \mathrm{gm} / \mathrm{kg}$, i.p. (Iwamoto et al., 1987). Carotid artery was cannulated to measure arterial blood pressure via a pressure transducer and ECG was monitored via subcutaneous stainless-steel electrodes. PowerLab (4/35) data acquisition system (ADInstruments, Castle Hill, Australia, Pty Ltd.) was utilized for blood pressure and ECG monitoring. Data were analyzed by LabChart7 software. After intubation of the trachea, the animals were put on positivepressure ventilation (frequency $65-70 / \mathrm{min}$, tidal volume $3 \mathrm{~mL}$ ), the thoracic cavity was opened and 6.0 silk suture was looped under the left descending coronary artery near the origin of the pulmonary artery (Zeng et al., 2008). Blood pressure and ECG were recorded before and immediately after ligation then 2 hours and 4hours thereafter. Shamoperated rats underwent the identical surgical procedure as described above except ligation of the coronary artery. Blood pressure and ECG were recorded in the control and sham-operated groups in the same time sequence like coronary ligated groups.

\section{Measurement of infarction size}

At the end of the study, ventricles of the hearts from six rats of each group were separated then sliced into $2 \mathrm{~mm}$ transverse sections thickness and incubated in $1 \%$ triphenyltetrazolium chloride (TTC) stain at $37{ }^{\circ} \mathrm{C}$ (prepared as $10 \mathrm{mg} / \mathrm{ml}$ of a $\mathrm{pH} 7.4$ phosphate buffer) for $20 \mathrm{~min}$ to visualize the infarct (pale) areas. The infarct size was expressed as infarct area\% of total sliced areas (Fishbein et al., 1981). Percent reduction in infarct size $=$ (infarct area\% of untreated MI group-infarct area\% of donepezil pretreated group)/ infarct area of untreated MI group x100 was calculated. 


\section{Assessment of catalase activity and reduced glutathione (GSH) content in the myocardium}

Two fragments of the left ventricle muscle from six rats of each group were resected. These fragments were weighed and placed separately inside cryotubes properly identified and put into container of liquid nitrogen then stored in a freezer at a temperature of $-80^{\circ} \mathrm{C}$ until the analysis. Evaluation of catalase activity was done according to Aebi and Bergmeyer (1974), while GSH level was assessed according to Sedlak and Lindsay (1968).

\section{TNF- $\alpha$ and cTnI assessment in serum}

Blood samples were collected from the arterial polyethylene cannula, centrifuged at $3000 \mathrm{rpm}$ for 15 minutes. Serum was collected and stored at $-20^{\circ} \mathrm{c}$ as aliquots for further spectrophotometric determination of TNF- $\alpha$; by a commercial ELISA kits (R\&D Systems, USA) (Rani et al., 2013) and cTnI; by a commercial ELISA kits (CUSABIO, China) (Bertinchant et al., 2003).

\section{Statistical analysis}

Data were expressed as means \pm SEM. Statistical comparison between different groups were made using one-way analysis of variances (ANOVA) followed by Tukey post-hoc test for multiple comparison. Statistical significance was set at $p$ value $<0.05$. Results were analyzed using the Statistical Package for the Social Sciences, version 17 (SPSS Software, SPSS Inc., Chicago, USA).

\section{Results}

\section{Effect of donepezil hydrochloride on myocardial infarct size}

In the control and sham operated groups, the myocardial tissue stained with TTC and appeared crimson red. In the myocardial infarction groups, infarcted areas appeared pale in color. The area $\%$ of infarction in the untreated myocardial infarction group was $51.16 \pm 4.20$, which significantly decreased to $37.15 \pm 2.74$ in donepezil hydrochloridepretreated group with a percent reduction approached $27 \%$. (Table $1 \&$ Figure 1)

Table 1: Effect of pretreatment with $\mathrm{DH}$ on myocardial infarct size in coronary ligated male albino rats $(n=6)$.

\begin{tabular}{lllll}
\hline Groups & Control & Sham operated & Untreated-MI & $\begin{array}{l}\text { DH-pretreated } \\
\text { MI }\end{array}$ \\
\hline $\begin{array}{l}\text { Myocardial } \\
\text { infarct size }(\%)\end{array}$ & 0 & 0 & $51.16 \pm 4.20^{*}$ & $37.15 \pm 2.74^{* \#}$ \\
\hline $\begin{array}{l}\text { Percent } \\
\begin{array}{l}\text { reduction } \\
\text { infarct size }\end{array}\end{array}$ & - & - & - & $27 \%$ \\
\hline
\end{tabular}

Data represent mean area $\%$ of infarction \pm SE. ${ }^{*}$ Significant with respect to control and sham operated groups, " significant with respect to untreated MI group. MI: myocardial infarction. DH: donepezil hydrochloride. $n=$ number of rats in each group. 


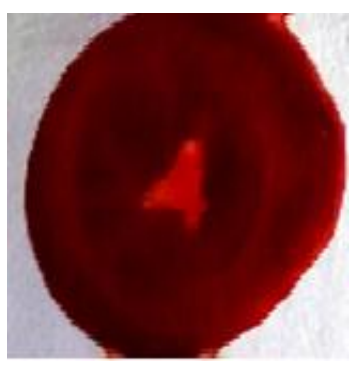

A

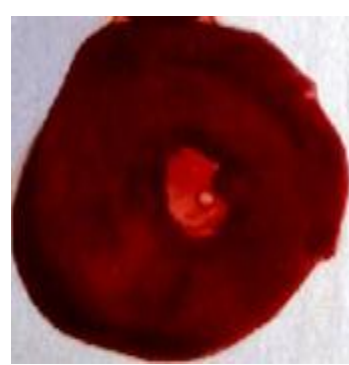

B

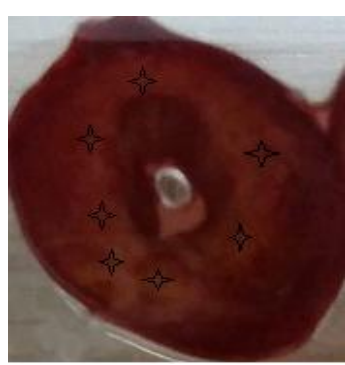

$\mathrm{C}$

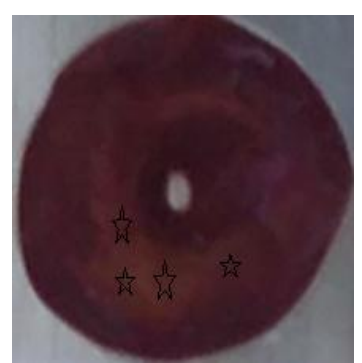

$\mathrm{E}$

Figure 1: Scanned images of TTC-stained ventricular slices from control (A) and shamoperated (B) groups as well as untreated (C) and donepezil-pretreated (E) infarction groups. Stars refer to the pale areas of infarction.

\section{Effect of donepezil on ECG recording}

Coronary artery ligation produced appearance of pathological Q-wave and significant increase in $\mathrm{T}$-wave voltage in the untreated group $(0.22 \pm 0.011,0.23 \pm 0.013$ and0.24 \pm 0.012 recorded immediately, 2 and 4 hours after ligation respectively) in relation to that before ligation $(0.06 \pm 0.002)$ in the same group as well as to control $(0.07 \pm 0.005,0.05 \pm 0.002$ and $0.07 \pm 0.004)$ and sham operated $(0.06 \pm 0.004,0.07 \pm 0.005$ and $0.05 \pm 0.003)$ groups. Pretreatment with donepezil hydrochloride before coronary ligation significantly reduced $\mathrm{T}$-wave voltage $(0.13 \pm 0.012,0.12 \pm 0.009$ and $0.14 \pm 0.011)$ in relation to the untreated myocardial infarction group with absence of pathological Qwave. (Table 2 and Figures $2 \& 3$ )

Table 2: T-wave voltage $(\mathrm{mV})$ in control, sham operated, untreated $\mathrm{MI}$, and $\mathrm{DH}-$ pretreated MI male albino rats $(\mathrm{n}=12)$.

\begin{tabular}{lllll}
\hline Groups & Control & Sham operated & Untreated-MI & $\begin{array}{l}\text { DH-pretreated } \\
\text { MI }\end{array}$ \\
\hline Before ligation & $0.06 \pm 0.004$ & $0.07 \pm 0.005$ & $0.06 \pm 0.002$ & $0.07 \pm 0.002$ \\
\hline $\begin{array}{l}\text { Immediately } \\
\text { after ligation }\end{array}$ & $0.07 \pm 0.005$ & $0.06 \pm 0.004$ & $0.22 \pm 0.011^{*}$ & $0.13 \pm 0.012^{* \#}$ \\
\hline $\begin{array}{l}2 \text { hours after } \\
\text { ligation }\end{array}$ & $0.05 \pm 0.002$ & $0.07 \pm 0.005$ & $0.23 \pm 0.013^{*}$ & $0.12 \pm 0.00 *^{* \#}$ \\
\hline $\begin{array}{l}\text { 4hours after } \\
\text { ligation }\end{array}$ & $0.07 \pm 0.004$ & $0.05 \pm 0.003$ & $0.24 \pm 0.012^{*}$ & $0.14 \pm 0.01 *^{* \#}$ \\
\hline
\end{tabular}

Data represent mean \pm SE of T-wave voltage $(\mathrm{mV}) .{ }^{*}$ Significant with respect to control and sham operated groups as well as to the respective mean value before ligation, "significant with respect to untreated MI groups as well as to the respective mean value before ligation. MI: myocardial infarction. DH: donepezil hydrochloride. $\mathrm{mV}$ : milli-Volt 


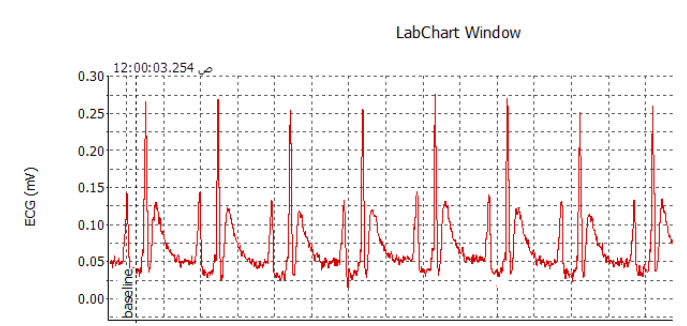

$\mathrm{C}$

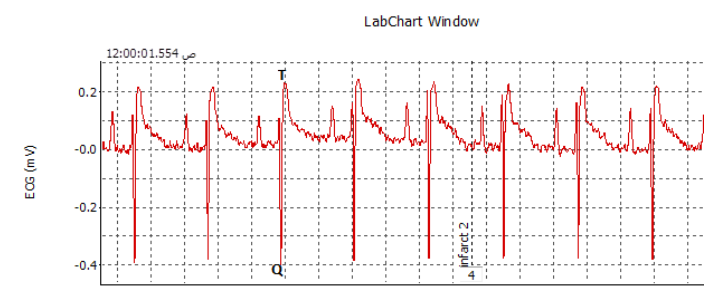

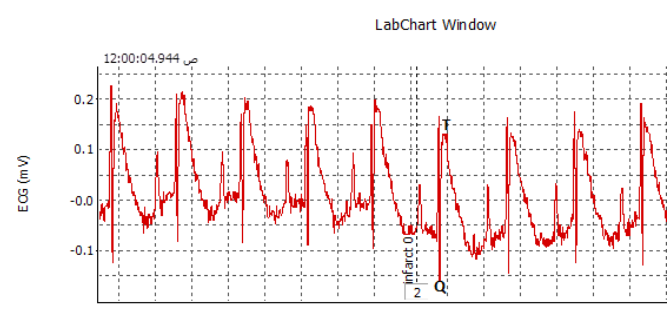

$\mathrm{D}$

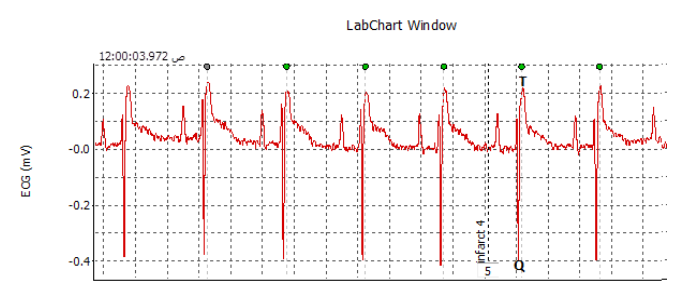

Figure 2: ECG from untreated-myocardial infarction group before (A) then immediately after coronary artery ligation (B) and 2 hours (C) as well as 4 hours (D) thereafter. Pathological Q-wave is prominent in ECG at time 0, 2, and 4hours after ligation ( $\mathrm{B}, \mathrm{C}$, and $\mathrm{D}$ respectively).

A

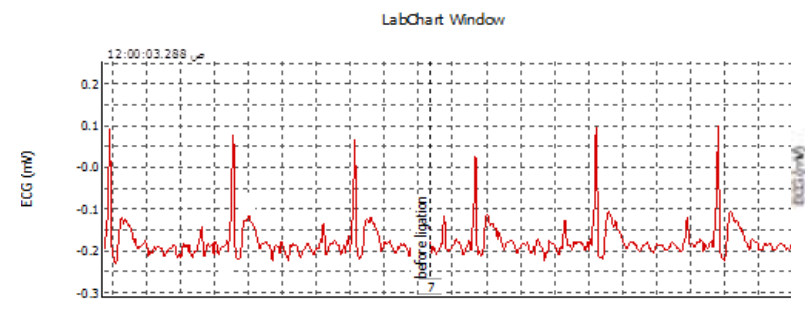

$\mathrm{C}$

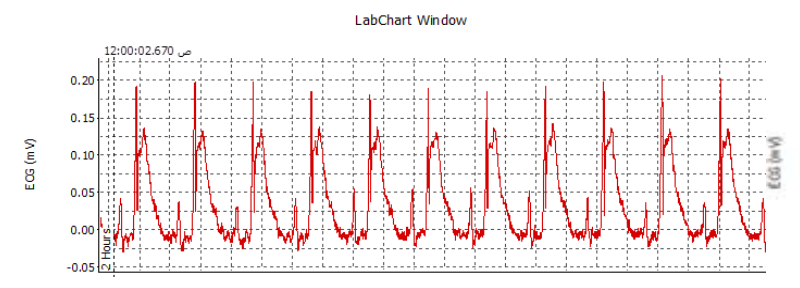

B

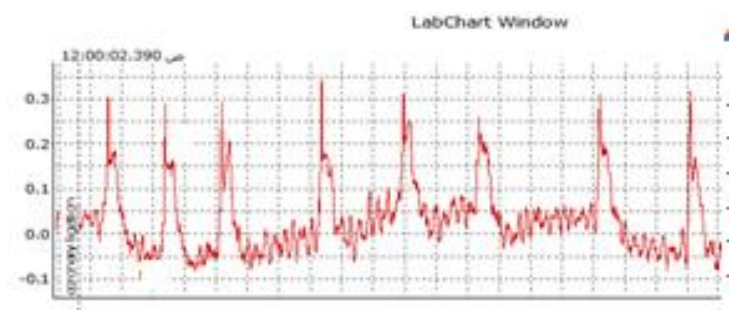

$\mathrm{D}$

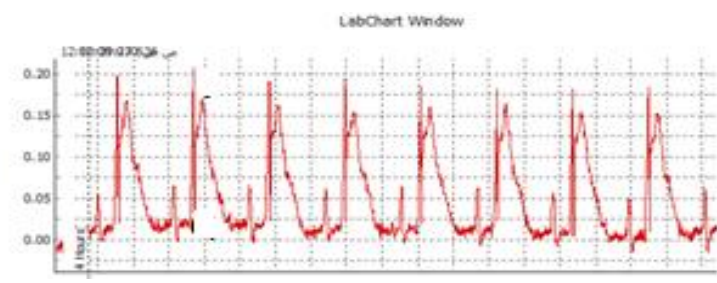

Figure 3: ECG from donepezil hydrochloride-pretreated myocardial infarction group before (A) then immediately after coronary artery ligation (B) and 2 hours (C) as well as 4 hours (D) thereafter.

\section{Effect of donepezil hydrochloride on heart rate and mean arterial pressure (MAP)}

Prior to coronary artery ligation, donepezil hydrochloride significantly $(\mathrm{P}<0.05)$ decreased heart rate to $241 \pm 19$ in relation to control, sham operated and untreated myocardial infarction groups $(292 \pm 15,285 \pm 19$ and $282 \pm 18$ respectively). Coronary artery ligation significantly $(\mathrm{P}<0.05)$ increased heart rate to $360 \pm 20,355 \pm 22$ and 
$358 \pm 18$ recorded immediately, 2 and 4 hours after ligation respectively in the untreated myocardial infarction group in relation to control $(290 \pm 13,280 \pm 17$ and $288 \pm 12)$ and sham operated $(292 \pm 11,286 \pm 13$ and $285 \pm 15)$ groups. In donepezil hydrochloridepretreated group, the heart rate was insignificantly changed after coronary ligation in relation to control and sham groups, while significantly $(\mathrm{P}<0.05)$ decreased $(279 \pm 15$, $283 \pm 11$ and $280 \pm 10)$ in respect to untreated $(360 \pm 20,355 \pm 22$ and $358 \pm 18)$ infarction group. (Figure 4)

Donepezil pretreatment produced insignificant change in MAP $(87 \pm 6.2)$ in relation to control, sham operated and untreated myocardial infarction $(91 \pm 7.4,88 \pm 6.1$ and $89 \pm 5.8)$ groups. Coronary artery ligation significantly $(\mathrm{P}<0.05)$ decreased MAP both in the untreated $(67 \pm 4.5,70 \pm 5.9$ and $66 \pm 4.1)$ and donepezil-pretreated $(66 \pm 4.1,68 \pm 5.4$ and 64 \pm 4.5 ) infarction groups recorded immediately, 2 and 4 hours after coronary ligation respectively in relation the control $(89 \pm 3.6,90 \pm 5.8$ and $91 \pm 4.6)$, and sham operated $(87 \pm 4.1,90 \pm 5.5$ and $90 \pm 5.1)$ groups. (Figure 5)

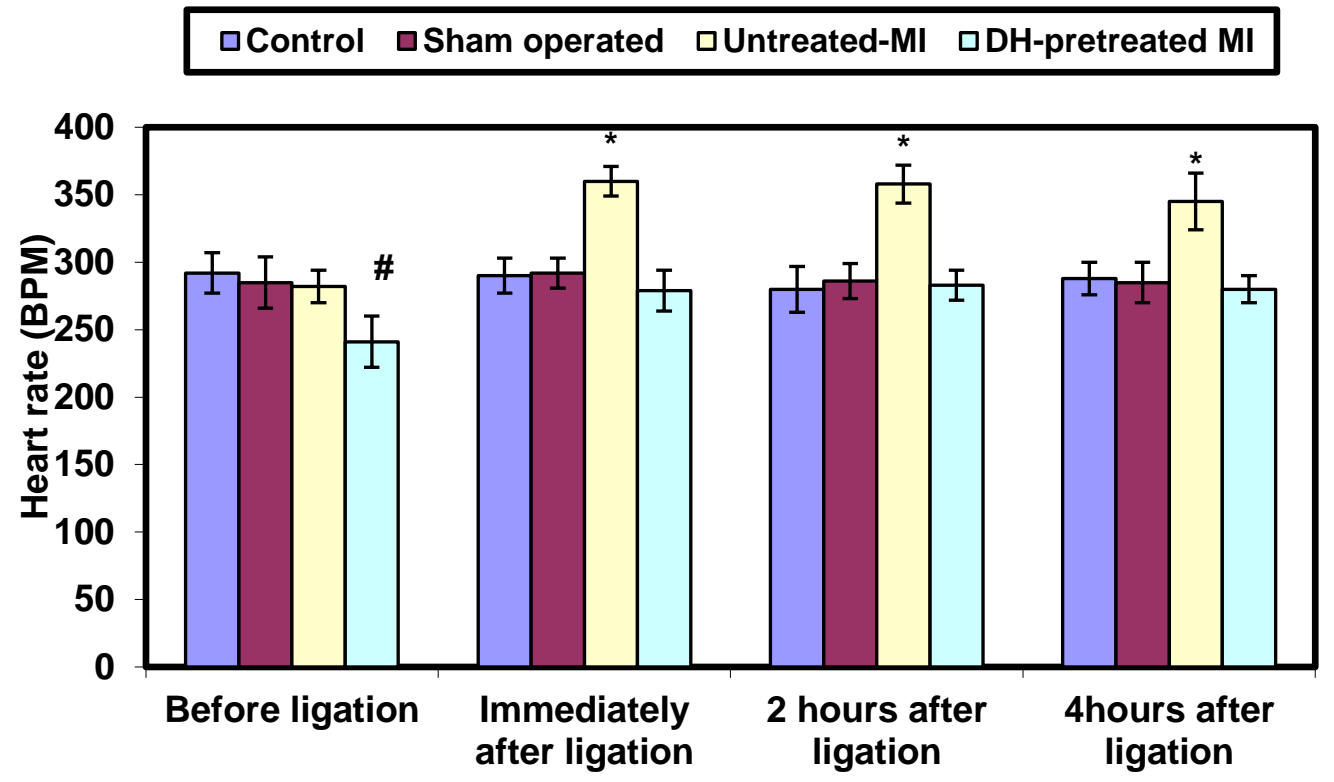

Figure 4: Heart rate in the control, sham operated, untreated MI, and DH pretreated MI groups. " Significant with respect to control, sham operated and untreated MI groups, * Significant with respect to control, sham operated and DH-pretreated MI groups. MI: myocardial infarction, DH: donepezil hydrochloride, BPM: beat per minute. 


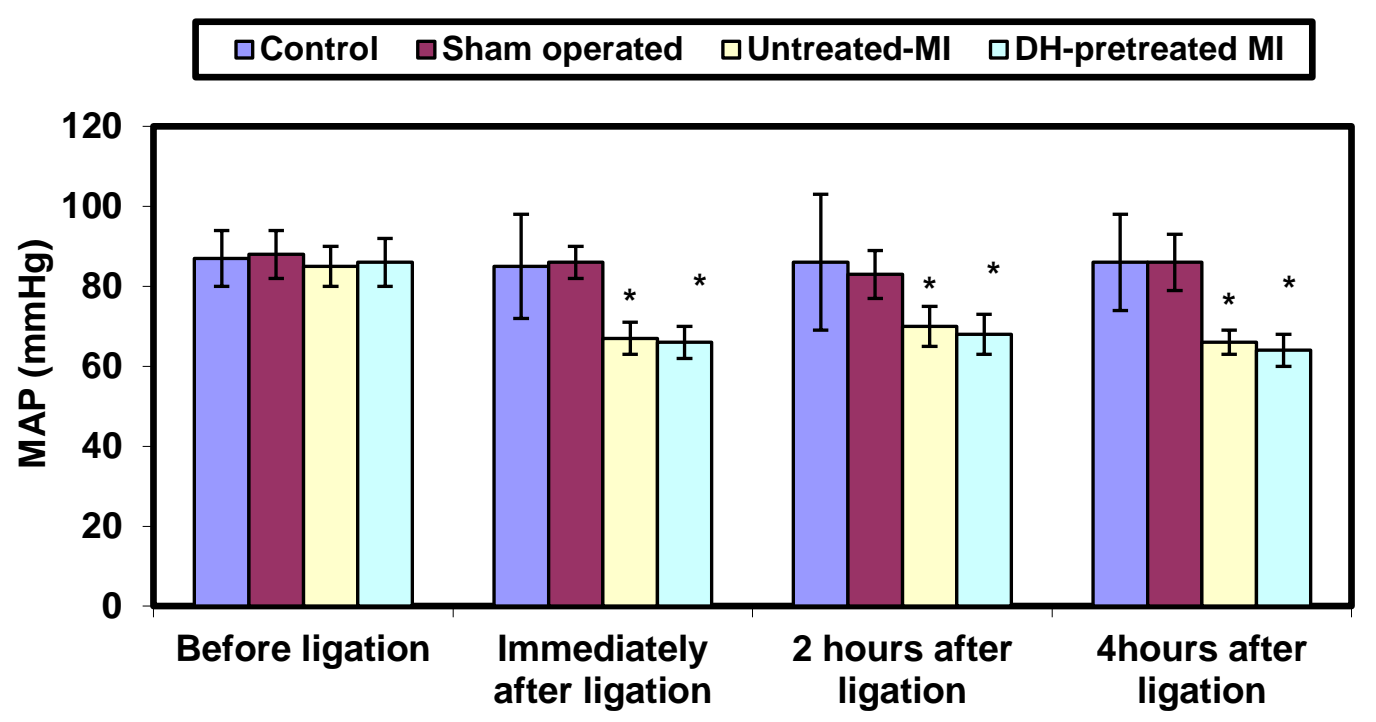

Figure 5: Mean arterial pressure in control, sham operated, untreated MI, and DH pretreated MI groups. *Significant with respect to control and sham operated groups. MI: myocardial infarction, DH: donepezil hydrochloride, MAP: Mean Arterial Pressure.

Effect of donepezil on reduced glutathione content and catalase activity in the myocardium

Coronary artery ligation significantly reduced glutathione content and catalase activity in the myocardium $(186 \pm 147 \& 1.2 \pm 0.15$ respectively) in the untreated infarction group in relation to control $(277 \pm 17 \& 2.8 \pm 0.22)$, and sham operated $(270 \pm 15 \& 2.6 \pm 0.19)$ groups. Donepezil pretreatment produced significant increase in reduced glutathione content and catalase activity $(235 \pm 21 \& 2.4 \pm 0.2$ respectively) in the myocardium in relation to untreated myocardial infarction group. (Figures $6 \& 7$ )

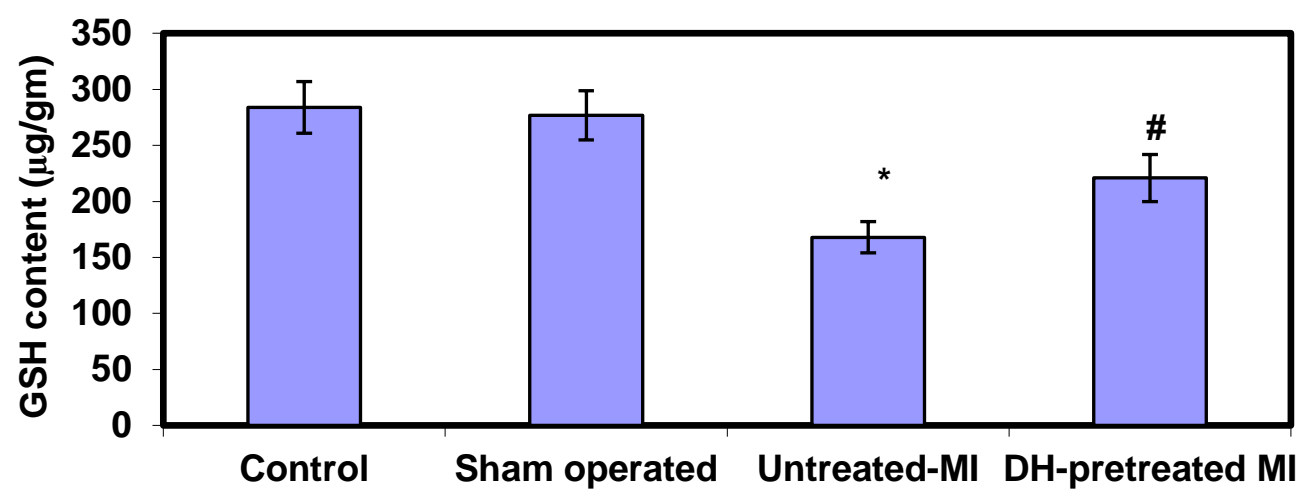

Figure 6: Reduced glutathione content $(\mu \mathrm{g})$ in control, sham operated, untreated MI, DH pretreated MI groups. * Significant with respect to control, sham-operated, and DHpretreated MI groups. ${ }^{\#} \mathrm{P}<0.05 \%$ versus control, sham operated and untreated $\mathrm{MI}$ groups. MI: myocardial infarction, DH: donepezil hydrochloride. GSH: reduced glutathione. 


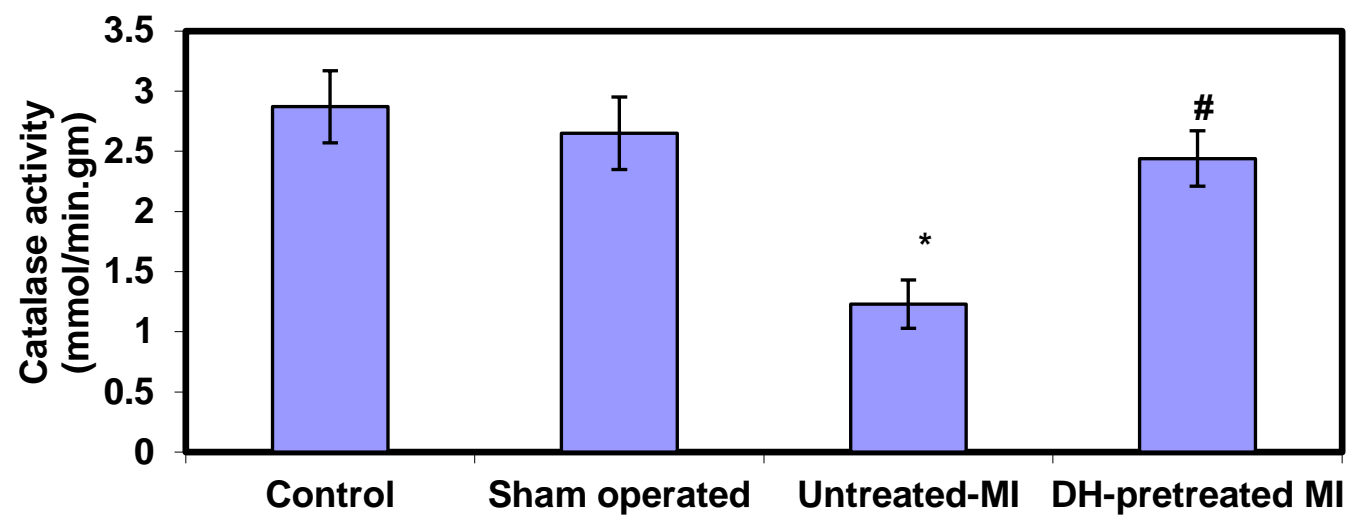

Figure 7: Catalase activity (mmol/min.gm) in control, sham operated, untreated MI, DH pretreated MI groups. * Significant with respect to control, sham-operated, and DHpretreated MI groups, " significant with respect to untreated MI group. MI: myocardial infarction, DH: donepezil hydrochloride.

\section{Effect of donepezil on serum levels of TNF $\alpha$ and cTnI}

In the untreated myocardial infarction group the serum levels of both $\mathrm{TNF} \alpha$ and cTnI had significantly $(\mathrm{P}<0.05)$ increased $(55 \pm 1.2$ and $142 \pm 12$ respectively) in relation to control $(7.2 \pm 0.3 \& 18 \pm 1.3)$, and sham operated $(6.4 \pm 0.4$ and $21 \pm 1.4)$ groups. Donepezil pretreatment produced significant $(\mathrm{P}<0.05)$ decrease in TNF $\alpha$ and cTnI levels $(35 \pm 2.8$ and $61 \pm 3.7$ respectively) in relation to untreated myocardial group. (Figures $8 \&$ 9)

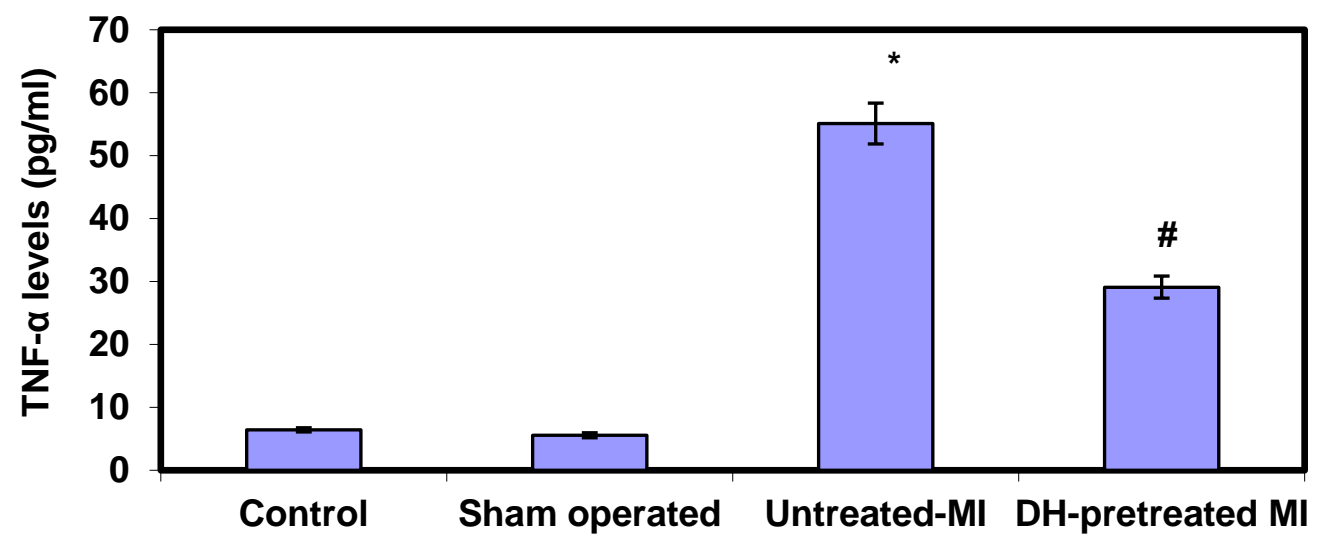

Figure 8: Tumor necrosis factor $(\mathrm{TNF}-\alpha)$ serum levels $(\mathrm{pg} / \mathrm{ml})$ in control, sham operated, untreated MI, DH pretreated MI groups. * Significant with respect to control, sham-operated, and DH-pretreated MI groups. \# Significant with respect to control, sham operated and untreated MI groups. MI: myocardial infarction, DH: donepezil hydrochloride. 


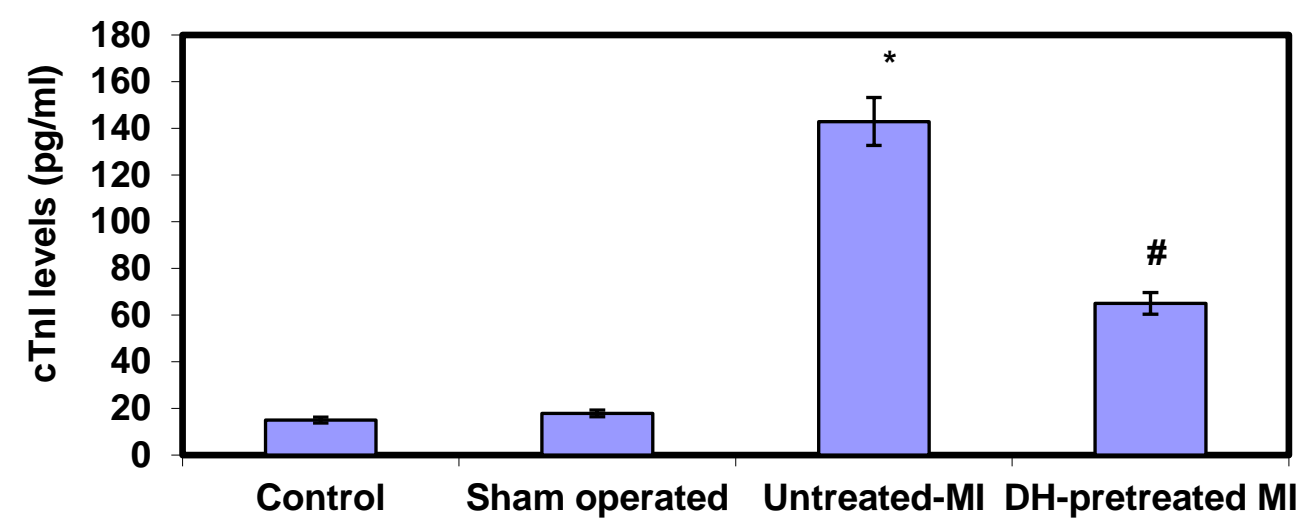

Figure 9: Cardiac Troponin I (cTnI) serum levels $(\mathrm{pg} / \mathrm{ml})$ in control, sham operated, untreated MI, DH-pretreated MI groups. * $\mathrm{P}<0.05 \%$ versus control, sham-operated, and DH-pretreated MI groups. ${ }^{\#} \mathrm{P}<0.05 \%$ versus control, sham operated and untreated MI groups. MI: myocardial infarction, DH: donepezil hydrochloride.

\section{Discussion}

Experimental myocardial infarction is induced by sequential administration of subcutaneous isoproterenol or an electrocautery technique applied to the epicardial surface as well as coronary artery ligation (Patten and Hall-Porter, 2009). Clinically, coronary artery occlusion induces myocardial necrosis leading to AMI. The primary goal of treatment in these patients is reducing the infarct size (Marchant et al., 2012). The present study utilized the left anterior descending coronary artery ligation method to induce myocardial infarction in rats. Coronary artery ligation produced AMI evidenced by (1) significant elevation of the T-wave voltage with appearance of pathological Q-wave in ECG, (2) pale areas (infarcts) in TTC-stained ventricular slices, and (3) elevation in plasma level of cTnI in relation to control and sham operated groups. Q-wave myocardial infarction was associated with larger infarct size and lower left ventricular ejection fraction (Delewi et al., 2013). The myocardial infarct size was assessed by TTCstaining of ventricular slices and correlated with the plasma level of cTnI. The viable myocardium can convert TTC by dehydrogenase enzyme to formazan (a red pigment) that stained the tissue crimson red. Non-viable (infarcted) myocardium lacks dehydrogenase enzyme so remains pale in color (Chen et al., 2014). The extent of cTnI elevation strongly correlates with infarct size, thus provides indication for the prognosis following myocardial infarction (Ahmet and Yesim, 2015).

ECG of donepezil-pretreated infarction group showed absence of pathological Q-wave as well as decrements the T-wave voltage. Area percentage of infarction and the plasma level of cTnI were decreased in relation to untreated myocardial infarction group. These findings revealed the anti-ischemic effects of donepezil. Experimental studies on the effect of donepezil on myocardial infarction are scarce. Arikawa et al. (2011) found that pretreatment with donepezil reduced the risk of left ventricular free wall rupture during the acute phase of myocardial infarction and chronic intervention with the drug played a beneficial role in suppressing long-term cardiac remodeling after myocardial infarction in mice. Moreover, Li et al. (2013) demonstrated that donepezil administration markedly improved the long-term survival of rats with chronic heart failure induced by extensive myocardial infarction. They found that pretreatment with the drug lowered the levels of plasma arginine vasopressin, brain natriuretic peptide, 
catecholamine, and tissue pro-inflammation markers. In the same context, the combined treatment with donepezil and losartan prevented the progression of cardiac dysfunction and improved the long-term survival of rats with extensive myocardial infarction ( $\mathbf{L i}$ et al., 2014).

Prior to coronary artery ligation, the heart rate was decreased in donepezilpretreated group in relation to control, sham, and untreated myocardial infarction groups. In the latter group, coronary artery ligation increased the heart rate with decrements in mean arterial pressure. However, in donepezil-pretreated group the heart rate did not increase after coronary artery ligation, while the mean arterial pressure was decreased relation to control, and sham operated groups. These results are in agreement with Li et al. (2014) who concluded that parasympathetic activation by donepezil significantly reduced heart rate but did not affect mean blood pressure. The negative chronotropic effect of donepezil hydrochloride depends on cholinesterase inhibition in the heart with subsequent cholinergic activation (Nenasheva et al., 2013). Clinically, a prospective study using donepezil hydrochloride in patients with Alzheimer's disease reported that, the drug produced a significant reduction in heart rate (Bordier et al., 2006). The negative chronotropic effect of donepezil hydrochloride with subsequent reduction of the myocardial oxygen requirements might contribute in the occurred reduction of the infarct size.

In the present study, AMI decreased catalase activity and reduced glutathione content in the myocardial tissue. Free radical scavenger enzymes, such as catalase, are the first line of defense against oxidative injury. During AMI, superoxide radicals modulate the activity of catalase, resulting in reduced activity of this enzyme and accumulation of superoxide radicals, with consequent damage to the myocardium (Saravanan and Prakash, 2004). Reactive oxygen species are generated in the early stages of AMI, and glutathione is involved in reducing free radical hydrogen peroxide, with decreased levels of glutathione in this period. Glutathione is important in protecting the myocardium against damage by free radicals and a reduction in its levels can compromise recovery after periods of ischemia (Stanely et al., 2009). Catalase activity and glutathione content in donepezil hydrochloride-pretreated group were significantly increased in relation to untreated myocardial infarction group. Attenuation of oxidative stress by donepezil pretreatment could decrease myocardial damage and infarct size after coronary artery ligation. These results are in agreement with Umukoro et al. (2014) who found that donepezil hydrochloride decreased oxidative stress via inhibition of glutathione depletion induced by scopolamine and lipopolysaccharide in mice brain. Moreover, Saxena et al. (2008) found that tacrine and donepezil, beside inhibition of acetylcholinesterase, also suppress oxidative stress in streptozotocin amnesic mice

The results of the present study showed that left coronary artery ligation increased the serum levels of TNF- $\alpha$. Indeed, the increased level of this proinflammatory cytokine in AMI coincides with the acute inflammatory response that could aggravate the necrosis and irreversible vascular endothelial cell injury as well as complement activation and free radical generation ( $\mathbf{L i}$ et al., 2011). The inflammatory reaction could aggravate myocardial injury and increase the infarct size after ischemia (Zeng et al., 2012). Moreover, TNF- $\alpha$ could promote cardiomyocyte apoptosis via metalloproteinases activation and impairment of expression of their inhibitors (Steffens et al., 2009), as well as regulating products that 
stimulate inflammation such as NF- $\mathrm{KB}$ and COX-2 (Domitrovic et al., 2011). The present findings demonstrated that pretreatment with donepezil hydrochloride significantly reduced the plasma levels of TNF- $\alpha$ in relation to untreated myocardial infarction group. These results could confirm the anti-inflammatory and anti-apoptotic effects of donepezil.

Indeed, Yuan et al. (2015) reported that donepezil hydrochloride inhibited the release of cytokines (TNF- $\alpha$, IL-1 $\beta$, IL-6 and IL18) and myocardial apoptosis in rats with ischemia reperfusion injury through alpha7 nicotinic acetylcholine receptor $(\alpha 7$ nAChRs)-dependent mechanism. The cholinergic anti-inflammatory pathway has been reported to acts on $\alpha 7-n A C h R s$ expressed on immune cells especially monocytes and macrophages (Fujisawa et al. 2010). Moreover, donepezil was reported to reduce intraand extracellular matrix metalloproteinase-9-related acute inflammatory tissue injury in the infarcted myocardium, thereby reduces the risk of left ventricular free wall rupture during the acute phase of myocardial infarction (Arikawa et al., 2014). Jiang et al. (2013) demonstrated that donepezil hydrochloride attenuated the inflammatory reaction in experimental autoimmune encephalomyelitis in mice. Furthermore, cholinergic activation was found to attenuate systemic inflammatory responses by inhibiting the production of pro-inflammatory cytokines from activated macrophages and other immune cells (Pavlov and Tracey, 2006).

In the present study, attenuation of the acute inflammatory tissue injury following AMI by donepezil could contribute in infarct size reduction. Indeed, cholinesterase inhibition with subsequent cholinergic activation was found to prevent the loss of functional gap junction channels in the heart and protect against ischemiainduced lethal arrhythmias (Ando et al., 2005). Moreover, cholinergic activation could protect cardiomyocytes against hypoxia through the phosphatidylinositol 3kinase/Akt/hypoxia inducible factor-1 $\alpha$ (PI3K/Akt/HIF-1 $\alpha$ ) pathway (Kakinuma et al., 2005). HIF- $1 \alpha$ is the major transcription factor activated to mediate adaptive responses under hypoxia and an important target modulating apoptosis resistance (Semenza, 2010).

\section{Conclusion}

Pretreatment with donepezil hydrochloride reduced myocardial infarct size in coronary artery ligation-induced myocardial infarction. This effect could be attributed to its bradycardiac and antioxidant actions as well as attenuation of myocardial inflammation.

\section{REFERENCES}

Aebi H., Bergmeyer H.U. (1974). Catalase in methods of enzymatic analysis. $2^{\text {nd }}$ ed. New York:Academic Press; p.673-84.

Ahmet Y., Yesim O. (2015). An overview of the significance of troponin in acute myocardial infarction. ActaMed. 4: 15-20.

Amsterdam E.A., Wenger N.K., Brindis, R.G., Casey, D. E.; Ganiats, T. G.; Holmes, D. R.; Jaffe, A. S.; Jneid, H.; Kelly, R. F.; Kontos, M. C.; Levine, G. N.; Liebson, P. R.; Mukherjee, D.; Peterson, E. D.; Sabatine, M. S.; Smalling, R. W. and Zieman, S. J. (2014). AHA/ACC Guideline for the management of patients with non-ST-elevation acute coronary syndromes: executive summary: A report of the American College of Cardiology/ American Heart Association Task Force on Practice Guidelines. J. Am. Coll. Cardiol.; 64(24):2645-2687. 
Ando M., Katare R.G., Kakinuma Y., Zhang D., Yamasaki F. (2005). Efferent vagal nerve stimulation protects heart against ischemia-induced arrhythmias by preserving connexin43 protein. Circulation 112: 164-170.

Arikawa M., Kakinuma Y., Handa T., Yamasaki F., Sato T. (2011). Donepezil, Anti-Alzheimer's Disease Drug, Prevents Cardiac Rupture during Acute Phase of Myocardial Infarction in Mice. PLoS ONE 6(7): e20629.

Arikawa M., Kakinuma Y., Noguchi T., Sato T. (2014). Donepezil, Therapeutic Acetylcholinesterase Inhibitor, Prevents the Progression of Ventricular Dysfunction by Promoting Myocardial Glucose Utilization in Rat Model of Chronic Heart Failure Following Myocardial Infarction. Cardiol Pharmacol 3: 121 .

Bertinchant J.P., Polge A., Juan J.M., Oliva-Lauraire M.C., Giuliani I., MartyDouble C., Burdy J.Y., Fabbro-Peray P., Laprade M., Bali J.P., Granier C., de la Coussaye J.E., Dauzat M. (2003). Evaluation of cardiac troponin $\mathrm{I}$ and $\mathrm{T}$ levels as markers of myocardial damage in doxorubicin-induced cardiomyopathy rats, and their relationship with echocardiographic and histological findings. Clin Chim Acta. 329(1-2):3951.

Bordier P., Garrigue S., Lanusse S. (2006). Cardiovascular effects and risk of syncope related to donepezil in patients with Alzheimer's disease. CNS Drugs 20: 411-417.

Castro R.R., Porphirio G., Serra S.M., Nobrega A.C. (2004). Cholinergic stimulation with pyridostigmine protects against exercise induced myocardial ischemia. Heart; 90: 1119 - 1123.

Chen T.L. ‘Zhu G.L., He X.L., Wang J.A., Wang Y., Qi G.A. (2014). Short-term pretreatment with atorvastatin attenuates left ventricular dysfunction, reduces infarct size and apoptosis in acute myocardial infarction rats. Int. J.Clin. Exp. Med. 7(12):4799-4808.

Delewi R., IJff G., van de Hoef T. (2013). Pathological Q Waves in Myocardial Infarction in Patients Treated by Primary PCI. J Am Coll Cardiol Img 6(3):324-331

Domitrovic R., Jakovacb H., Blagojevic G. (2011). Hepatoprotective activity of berberineis mediated by inhibition of TNF- $\alpha, \mathrm{COX} 2$ and iNOS expression in CCl4-intoxicated mice. Toxicology 280(1-2):33-43.

Fishbein M.C., Meerbaum S., Rit J., Londo U., Kanmatsuse K., Mercier J.C., Corday E., Ganz W. (1981). Early phase acute myocardial infarct size quantification: validation of the triphenyl tetrazolium chloride tissue enzyme staining technique. Am Heart J; 101:593-600.

Frangogiannis N.G. (2012). Regulation of the inflammatory response in cardiac repair. Circ Res. 6;110(1):159-73.

Fujiki M., Kobayashi H., Uchida S., Inoue R., Ishii K. (2005). Neuroprotective effect of donepezil, a nicotinic acetylcholine-receptor activator, on cerebral infarction in rats. Brain Res 1043: 236-241. 
Fujisawa M., Murata T., Hori M. (2010). The 5-HT4 receptor agonist mosapride attenuates NSAID-induced gastric mucosal damage. J. of Gastroenterology; 45:179-186.

Gelpi R.J. (2016). Cardiovagal activity confers cardioprotection after myocardial infarction: recent advances. Experimental physiology 101(5): 563-564.

Iwamoto K., Watanabe J., Atsumi F. (1987). Effects of urethane anesthesia and age on organ blood flow in rats measured by hydrogen gas clearance method. $J$ Pharmacobiodyn.; 10(6):280-284.

Jiang Y., Zou Y., Chen S., Zhu C., Wu A., Liu Y., Ma L., Zhu D., Ma X., Liu M., Kang Z., Pi R., Peng F., Wang Q., Chen X. (2013). The anti-inflammatory effect of donepezil on experimental autoimmune encephalomyelitis in C57 BL/6 mice. Neuropharmacology. Oct;73:415-24.

Kakinuma Y., Ando M., Kuwabara M., Katare R.G., Okudela K. (2005). Acetylcholine from vagal stimulation protects cardiomyocytes against ischemia and hypoxia involving additive non-hypoxic induction of HIF1alpha. FEBS let 579: 2111-2118.

Li C., Gao Y., Xing Y., Zhu H., Shen J., Tian J. (2011). Fucoidan, a sulfated polysaccharide from brown algae, against myocardial ischemia-reperfusion injury in rats via regulating the inflammation response. Food Chem.Toxicol. 49:2090-2095.

Li M., Zheng C., Kawada T., Inagaki M., Uemura K., Shishido T., Sugimachi M. (2013). Donepezil markedly improves long-term survival in rats with chronic heart failure after extensive myocardial infarction Circ J; 77: 2519 2525

Li M., Zheng C., Kawada T., Inagaki M., Uemura K., Sugimachi M. (2014). Adding the acetylcholinesterase inhibitor, donepezil, to losartan treatment markedly improves long-term survival in rats with chronic heart failure. Eur J of Heart Fail 16, 1056-1065

Marchant D.J., Boyd J.H., Lin D.C., Granville D.J., Garmaroudi F.S., McManus B.M. (2012). Inflammation in myocardial diseases. Circ. Res. 110(1):126-144.

Monacelli F., Odetti P., Sartini M., Parodi A., Brunelli C., Rosa G., 2014. Cardioprotection and Anticholinesterases in Patients with Alzheimer disease: Time for Reappraisal. Dement Geriatr Cogn Disord Extra 4:45-50

Montecucco F., Carbone F., Schindler T.H. (2016). Pathophysiology of ST-segment elevation myocardial infarction: novel mechanisms and treatments. Eur Heart J 37, 1268-1283.

Moran A.E., Forouzanfar M.H., Roth G.A., Mensah G.A., Ezzati M., Flaxman A., Christopher J.L., Naghavi M. (2014). The global burden of ischemic heart disease in 1990 and 2010: the Global Burden of Disease 2010 study. Circulation 129: 1493-1501.

Nenasheva T.A., Neary M., Mashanov G.l. (2013). Abundance, distribution, mobility and aligomeric state of M2 muscarinic acetylcholine receptors in live cardiac muscle. J Mol Cell Cardiol 57: 129-136. 
Patten R.D., Hall-Porter M.R. (2009). Small Animal Models of Heart Failure: Development of Novel Therapies, Past and Present. Circ Heart Fail. 2:138144

Pavlov V.A., Tracey K.J. (2006). Controlling inflammation: the cholinergic antiinflammatory pathway. Biochem Soc Trans 34: 1037-1040.

Rani N., Bharti S., Manchanda M., Nag T.C., Ray R. (2013). Regulation of Heat Shock Proteins 27 and 70, p-Akt/p-eNOS and MAPKs by Naringin Dampens Myocardial Injury and Dysfunction In Vivo after Ischemia/Reperfusion. PLoS ONE 8(12): e82577.

Reagan-Shaw S., Nihal M., Ahmad N. (2008). Dose translation from animal to human studies revisited. FASEB J 22:659-661

Sarapultsev P., Chupakhin O., Sarapultsev A., Rantsev M., Sidorova L., Medvedeva S., Danilova I. (2012). New insights in to the treatment of myocardial infarction International Journal of Pathology 93, 18-23

Saravanan G, Prakash J. (2004) Effect of garlic (Allium sativum) on lipid peroxidation in experimental myocardial infarction in rats. $\mathbf{J}$ Ethnopharmacol. 94(1):155-8.

Saxena G., Singh S., Argawal R., Nath C. (2008). Effect of donepezil and tacrine on oxidative stress in intracerebral streptozotocin-induced model of dementia in mice. Eur J of Pharmacol 581(3):283-9.

Sedlak J., Lindsay R.H. (1968). Estimation of total, protein-bound, and nonprotein sulfhydryl groups in tissue with Ellman's reagent. Anal Biochem 25(1):192205.

Semenza G.L. (2010). Oxygen homeostasis. Wiley Interdiscip Rev Syst Biol Med. 2 (3): $336-361$.

Stanely P, Priscilla H, Devika PT. (2009). Gallic acid prevents lysosomal damage in isoproterenol induced cardiotoxicity in Wistar rats. Eur J Pharmacol. 615(13):139-43.

Steffens S., Montecucco F., Mach F. (2009). The inflammatory response as a target to reduce myocardial ischaemia and reperfusion injury. Thromb.Haemost. 102:240-247.

Umukoro S., Adewole F. A., Eduviere A. T., Aderibigbe A. O., Onwuchekwa C. (2014). Free Radical Scavenging Effect of Donepezil as the Possible Contribution to its Memory Enhancing Activity in Mice. Drug Res (Stuttg) 64(5): 236-239

Wang T., Lv P., Jin W., Zhang H., Lang J., Fan M. (2014). Protective effect of donepezil hydrochloride on cerebral ischemia/reperfusion injury in mice. Mol Med Rep 9: 509-514.

Winblad B., Engedal K., Soininen H. (2001). A 1-year, randomized, placebocontrolled study of donepezil in patients with mild to moderate AD. Neurology 57: 489-495. 
Winblad B., Kilander L., Eriksson S., Minthon L., Båtsman S., Wetterholm A.L., Jansson-Blixt C., Haglund A. (2006). Donepezil in patients with severe Alzheimer's disease: double-blind, parallel-group, placebo-controlled study. Lancet 1;367(9516):1057-65.

Yuan X., Teng X., Hou J. (2015). Recipient Treatment With Donepezil, an Acetylcholinesterase Inhibitor, Abolishes Donor Heart Ischemia/Reperfusion Injury and Chronic Graft Failure Through TNF Inhibition in Syngenic Rat Model. Circulation; 132: A17722.

Zeng M., Yan H., Chen Y., Zhao H.J., Lv Y., Liu C., Zhou P., Zhao B. (2012). Suppression of NF-אB reduces myocardial no-reflow. PLoS One 7(10):e47306.

Zeng X., He H., Yang J., Yang X., Wu L., Yu J., Li L. (2008). Temporal effect of Guanxin No. 2 on cardiac function, blood viscosity, and angiogenesis in rats after long-term occlusion of the left anterior descending coronary artery. J Ethnopharmacol 118: 485-494. 


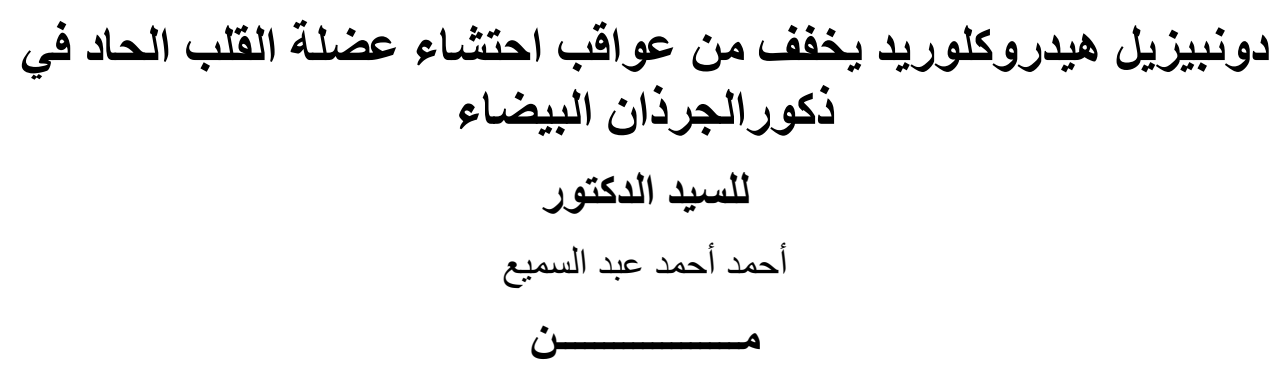

قسم الفارماكولوجيا الاكلينيكية ـ كليةالطب البشري- جامعة الزقازيق

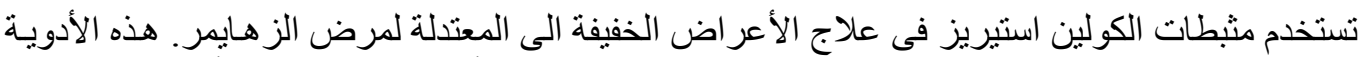

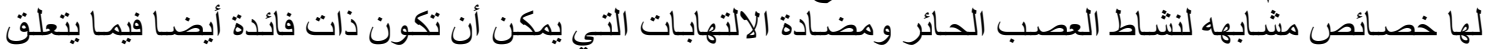
بأمر اض القلب و الأوعية الدموية.

الههف: يهدف البحث الى دراسة تأثير دونبيزيل هيدروكلويد على احتشاء عضلة القلب الحاد المحدث بربط الثريان التاجي في ذكور الجرذان البيضاء.

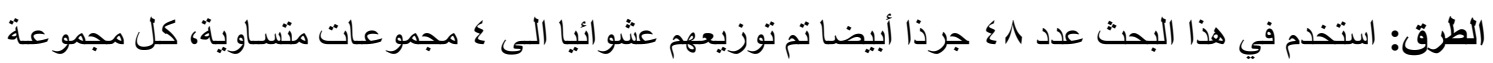
تحتوي على ب ا جرذا: المجمو عة الأولى (الضابطة): وتم إعطاؤها هاء مقاء مقطر بالفم يوميا لمدة حأيام.

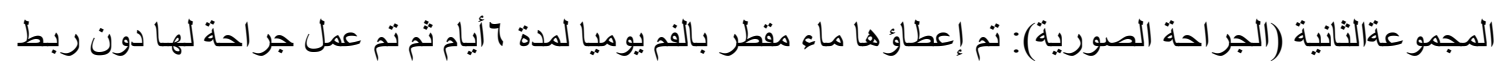
الثريان التاجي.

المجموعةالثالثة (الاحتشاء): وتم إعطاؤها ماء مقطر بالفم يوميا لمدة حأيام ثم تم ربط الثريان التاجي الأيسر .

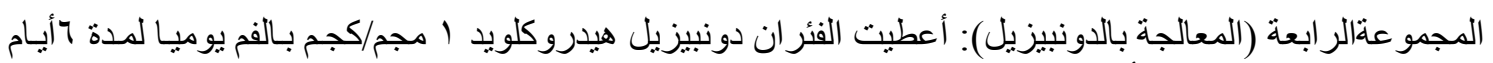
قبل ربط الثريان النتاجي الأيسر.

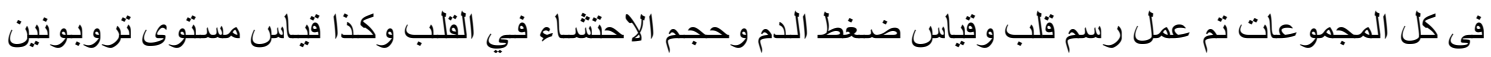
القلب-I و عامل نخر الورم-الفا فى المصل، بالاضـافة الى فاعلية إنزيم كتاليز و محتوى الجلوتاثيون فى عضلة ترونة

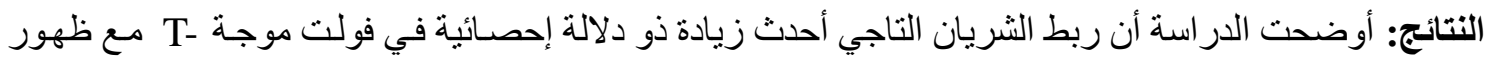

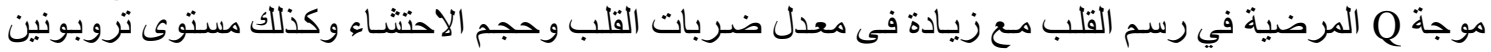

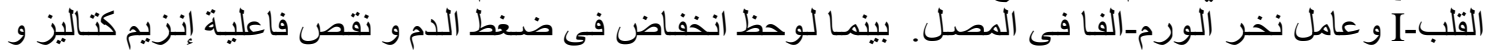

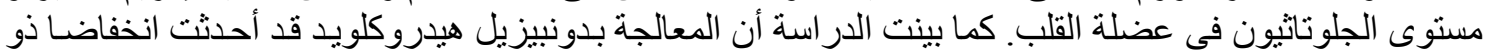

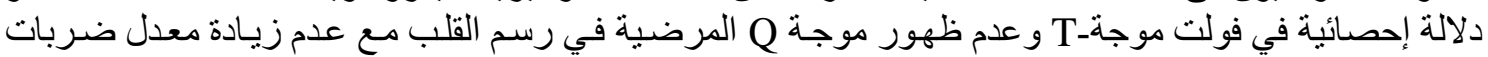

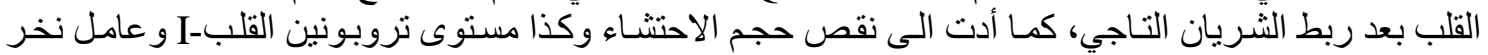

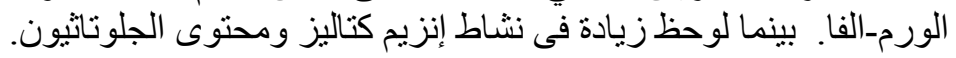

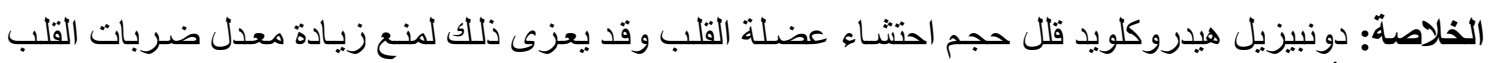

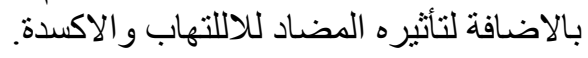

